\title{
Paediatrics at the cutting edge: do we need clinical ethics committees?
}

\author{
Victor F Larcher, Bryan Lask and Jean M McCarthy Great Ormond Street Hospital for Children, London
}

\begin{abstract}
Objectives - To investigate the need for hospital clinical ethics committees by studying the frequency with which ethical dilemmas arose, the perceived adequacy of the process of their resolution, and the teaching and training of staff in medical ethics.

Design - Interviews with individuals and three multidisciplinary teams; questionnaire to randomly selected individuals.

Setting - Two major London children's hospitals. Results - Ethical dilemmas arose frequently but were resolved in a relatively unstructured fashion. Ethical concerns included: the validity of consent for investigations and treatment; lack of children's involvement in consent; initiation of heroic or futile treatments; resource allocation. Staff expressed the need for a forum which would provide consultation on ethical issues, develop guidelines for good ethical practice, undertake teaching and training, and provide ethical reflection outside the acute clinical setting.

Conclusion - Multidisciplinary, accountable and audited clinical ethics committees with predominantly advisory, practice development and educational roles could provide a valuable contribution to UK clinical practice and perhaps in other countries that have not developed hospital clinical ethics committees.
\end{abstract}

\section{Introduction}

Contemporary paediatric practice increasingly poses ethical dilemmas for all members of the multidisciplinary team, irrespective of their seniority. These include:

(a) whether treatment should be started, discontinued or withheld ${ }^{12}$;

(b) whether children can consent to or refuse treatment $^{34}$;

(c) the allocation of scarce resources ${ }^{5}$;

(d) in what circumstances confidentiality should be breached.

\section{Key words}

Clinical ethics committees; paediatric practice.
The ethical permissibility of experimental investigations or treatment, for example covert video surveillance, multiple organ transplants and xenografting have also been the subject of controversy between professionals and the focus of media interest. $^{6}$

Despite a growing interest in health care ethics in the UK, there is no clear view as to how individual provider units might attempt to resolve ethical dilemmas which they face. In the USA and elsewhere some units have established institutional or clinical ethics committees (CECs) whose function has mainly been to provide a forum for ethical debate, analysis and evaluation, for both topics and cases. ${ }^{7-9}$ Although over two-thirds of US paediatric units have CECs no purely child-focused CECs exist in the UK, despite the specialised problems posed by paediatric practice. The function of a UK ethics committee has recently been described ${ }^{10}$ but we are aware of no prospective studies which might indicate the need for CECs in the UK.

To address this question the Great Ormond Street Hospital for Children NHS Trust set up a working party, whose terms of reference were:

(a) to determine the nature of ethical dilemmas and the frequency with which they arose;

(b) to examine the nature and adequacy of methods for dealing with them;

(c) to determine what teaching and training staff received;

(d) to explore what relationships might exist with the established research ethics committee (REC).

This paper describes the methods adopted by the working party to obtain information, its findings and recommendations.

\section{Methods}

Information was obtained using three forms of investigation:

1) Discussions concerning the nature and frequency of ethical issues were held with a wide range of health care workers of all degrees of seniority. 
Responses were used to determine the content of the questionnaire.

2) A questionnaire comprising 44 questions and opportunity for comment was administered to 60 randomly selected staff from all disciplines, irrespective of seniority. The stem of the question (see example) identified a particular issue and the four-part response (scored 1-4) gave information concerning the frequency with which such issues arose. Average scores of greater than two were felt to reflect ethical concerns.

3) Semi-structured interviews were held with members of multidisciplinary teams from three units (one general medical, one specialist medical and one surgical). The purpose of the interviews was to explore questions raised by the terms of reference of the working party.

\section{Clinical ethics questionnaire - sample question}

\section{Stem}

How often do you think that adequate information about proposed investigations is given to parents?

Response and Score

usually/often/occasionally/ rarely

$\begin{array}{llll}1 & 2 & 3 & 4\end{array}$

Scores of $>2$ reflect ethical concerns.

\section{Results}

A - THE NATURE AND FREQUENCY OF ETHICAL DILEMMAS

\section{General comments}

We found that ethical dilemmas arose frequently in clinical practice, irrespective of the type of unit or its degree of specialisation. There was general interest in ethical issues and enthusiasm for the establishment of a forum for ethical debate, analysis and guidance. Preference was expressed for such a forum to be both multidisciplinary and non-hierarchical. Many expressed an interest in active participation and a wish for education in this area.

Specific concerns which arose during discussion were broadly those which emerged from response to the questionnaire (see below).

Some interviewees expressed concern that an ethics committee might impose a further bureaucratic level upon already difficult treatment decisions. Fears were expressed that clinical ethics committees might produce erosion of clinical freedom, undermining of the clinician's role, and an adverse effect on the doctor-patient relationship. There were also concerns at the extra time which might be involved if clinical ethics committee consultation was mandatory and the ensuing effect on service provision.

\section{Response to the questionnaire}

The overall response rate was $60 \%$. Responses to 20 of 44 questions gave scores $(>2)$ indicating ethic concerns, with three questions scoring $>2 \cdot 5$. Thrit specific concerns identified were:

(i) The adequacy of information given (especials concerning investigations and medical as opposed to surgical treatments) and the adequacy of bots parents' and children's understanding of the naturg: and purpose of all types of investigations and treas ment. Constraints of both time and space were feft to exert pressure on children and parents to consenth which raised questions about the truly voluntar $\vec{B}$ nature of the consent. A number of respondents specifically commented on the difficulties of obtaintw ing truly informed consent from ethnic minorie families whose understanding of English was poo (ii) Lack of involvement of children in obtaininisy consent and the infrequency with which the child's views were expressed or considered in treatmeris decisions.

(iii) The initiation of treatments which were distress? ing, heroic, experimental or futile and their con-tinuation even in the face of a poor prognosis. As corollary, the tendency for families not to be offeres routinely and sensitively, terminal care as an alterna tive.

(iv) Some respondents felt that it was appropriate that psycho-social factors should determine whe or not treatment was given.

(v) The majority of those questioned would agree so requested by child or parent, to keep secref information which might otherwise alter the child क्ष treatment.

(vi) Difficulties in deciding how competing claim for scarce resources might fairly be decided.

B - THE METHODS FOR DEALING WITH ETHICAL

ISSUES AND THEIR PERCEIVED ADEQUACY

The main multidisciplinary forum for discussion of ethical issues and dilemmas was the unit or psychọ. social meeting, although occasionally ethical aspecs of particular cases were discussed at regular hospita clinical presentations (grand rounds). Such discus sions were criticised as being ad hoc, unstructurea and constrained by time. Individual members multidisciplinary teams tended to discuss issues within their own discipline and often with theif peers, rather than senior or juniors. There was general view that this was unsatisfactory, since it left tensions within teams and issues unresolved. Marry felt that more public discussions of ethical issues away from acute clinical settings was desirable and could be achieved by a forum which would alșe have consultative, educational and policy-generating functions.

A view was strongly expressed that such a bod should not try to decide individual cases and shou not erode or threaten clinical freedom or integrit The forum should be open to all who sought its advice. 
C - TEACHING AND TRAINING CONSIDERATIONS

Nursing staff had received formal regular training in the theory of health care ethics at pre- and postdiploma levels (post-registration students receive 30 hours' teaching per annum); ongoing ethics teaching and training was provided in professional development courses. Although doctors should now have received training in health care ethics as undergraduates, not all currently employed medical staff had done so. Arrangements for postgraduate medical training were restricted and unstructured compared with those for nurses. However, many clinicallybased postgraduate courses which were available to medical staff did have an ethics component.

\section{D - RELATIONSHIP WITH THE RESEARCH ETHICS COMMITTEE (REC)}

Many respondents and interviewees drew a distinction between research into ethical issues involving the disciplines of moral philosophy and the law, and the ethical basis of research which was the proper concern of local research ethics committees (LRECs). It was acknowledged that in some areas, for example the introduction of experimental or innovative treatments, there could be overlap between the areas of interest of both clinical and research ethics committees. Members of many LRECs do receive proleptic training and it was felt that this was an appropriate model for any clinical ethics group. The composition of LRECs, which include medical, nursing and lay members, was thought to be appropriate for clinical ethics groups, but it was felt that there should also be social work, chaplaincy, and perhaps legal representation.

\section{Discussion}

We found that ethical dilemmas arose frequently in clinical practice irrespective of the degree of seniority or specialisation of the staff involved. It was perhaps not surprising that responses to almost half the questions in the questionnaire reflected ethical concerns and that the mechanism for addressing them was considered ad hoc, unstructured and neither multidisciplinary nor non-hierarchical. However, there was considerable interest in health care ethics as evidenced by support for an ethics forum. Four desirable functions were identified; (a) consultation, but not prescription, on ethical issues including those which were case-related; (b) participation in development of guidelines for good clinical practice (c) education and (d) reflection on ethical issues away from the acute clinical setting.

In the USA these functions have been fulfilled by clinical ethics committees (CECs) ${ }^{7-9}$ which have been an established feature for over a decade. The percentage of US hospitals having CECs rose from 3\% in 1982 to over $50 \%$ by $1985 .{ }^{7}$ In contrast establishment of CECs in the UK and Europe has been slow ${ }^{10}$ though a number now exist or are in the process of formation. An initial important driving force behind the formation of US ethics committees was the need for a mechanism to help resolve difficult ethical issues in specific cases, for example, withdrawal of treatment for patients with persistent vegetative state. ${ }^{11}$ This role was supported by the President's Commission ${ }^{12}$ and is one in which the greatest experience has been accumulated, enabling the identification of both advantages and disadvantages of CECs. ${ }^{13-14}$

We need to examine whether this experience, as applied to the four functions our study identified, supports the need for an ethics committee and if so, how it might operate to maximise advantage and minimise disadvantage.

\section{a - To offer consultation but not prescription on ethical issues}

This function clearly includes identification and analysis of ethical issues arising in individual cases, as is the case in US committees ${ }^{9}$ and in a recently described UK one. ${ }^{10}$

The benefits claimed for this approach include:

(i) satisfying the request of health care professionals and public for guidance on ethical matters and helping resolve disputes within the multidisciplinary team.

(ii) ensuring the relevant information has been obtained, imparted and understood by decisionmakers, hence facilitating communication between professionals and families.

(iii) separating ethical from technical issues.

(iv) providing support for both staff and families, especially by formally acknowledging the complexity of the ethical issues faced.

(v) advising when it seems that legal intervention might be necessary to resolve a dispute or establish a new principle of law.

This approach would satisfy some of the concerns raised by our study - for example the adequacy of information given and its understanding in relation to treatment decisions. It would be also likely to facilitate delivery of health care sensitive to the needs of children and their families.

However, the US experience has identified important pitfalls associated with case consultation, which should be appreciated and avoided if CECs are to safeguard clients' freedom of choice and avoid seeking to impose solutions by a further bureaucratic process. Clinical ethics committees should avoid (i) reaching a consensus too readily, (ii) accepting secondhand or hearsay information and (iii) overlooking innovative ways of settling disputes by allowing sufficient time for information to be gathered and expertise to be sought. ${ }^{14}$ They need to consult widely, have few restrictions on access and be consultative rather than prescriptive. ${ }^{15}$ 
The obligation to consult a committee in specific cases, for example discontinuation of life-sustaining treatment, has been disputed. Some have advocated mandatory consultation but optional implementation and this is implicit in guidelines from both the American Medical Association ${ }^{13}$ and the President's Commission. ${ }^{12}$ However, most CECs adopt an optional/optional policy in that consultation is voluntary and decisions are non-binding. ${ }^{7}$ The latter maximises the educational function of CECs and is likely to have most acceptance in the UK.

A view is emerging from US practice that the case consultation function of a CEC is best fulfilled by a small group of individuals who are able to devote sufficient time to confidential analysis and evaluation. Employment of either a specific ethical consultant (the "grand master" approach) or a large committee approach (the "grand round" approach) introduces potential for bias and narrow perspectives on complex ethical situations. ${ }^{9}$ Such experience as exists in the UK indicates that a purely case consultative committee might, at present, have very little active function. ${ }^{10}$

However, the functional requirements we have discussed are not unique to case review ethics and we might expect that a CEC, in fulfilling a prospective analytical function on wider issues, would call on whatever expertise might be appropriate in order to provide an informed, reasonable and justifiable opinion.

\section{b - To participate in development of guidelines for good ethical practice}

Retrospective review of decisions in cases that have aroused ethical controversy enables the appropriateness of those decisions to be reviewed, with the hope that future cases may be better handled. An important consequence of this "moral audit" is the contribution that CECs may make to the development of integrated standards and guidelines, directed at enhancing good ethical practice and improving patient care. These include specific hospital ethics guidelines and others in which there is a significant ethical impact. Examples include Do Not Resuscitate (DNR) orders and consent and withdrawal of treatment guidelines. We would argue that the US experience with case consultative committees suggests that policy development and evaluation may be the most important role of future CECs. Although one outcome is likely to be the reduction of future conflict and controversy there will also be educational consequences, which we now consider.

\section{c - To educate health care professionals in health care ethics}

In order to fulfil this function it is crucial that members of CECs are themselves trained in ethical and legal analysis in an analogous fashion to those of LRECs by : i) becoming more familiar with ethical principles concepts and theories;

ii) studying relevant cases, policies and legislation $\overrightarrow{\overrightarrow{0}}$.

iii) receiving specific training by individuals witọ appropriate expertise;

iv) having access to relevant literature.

In this way a core group can be identified who are knowledgeable about medico-legal and ethical issue and are committed to developing their expertise? With increased specialisation in hospital medicine i could be argued that such a group contributes exper $\overline{0}$ tise which otherwise might not be available and in itself can institute teaching and training for othew members of staff.

\section{d - To permit reflection on ethical matters away from the acute clinic settings}

To some extent this is a combination of all the above functions, but with the important proviso that time is available for information-gathering, a proper debat of the issues and reflection. Attention to these details should avoid the pitfalls described by US authors. ${ }^{13} 1 \Phi$ It would be more important for such a group to be multidisciplinary so as to support the concept of mpll-v tidisciplinary working and holistic care. With increasi ing concerns about the inhumane nature of so modern medicine ${ }^{16}$ this function would be of cên siderable value.

All four functions would potentially increas chances of arriving at decisions which are bot rationally and ethically sound, and enhance bot? professional and patient autonomy in partnership when facing difficult ethical decisions. Much indecif sion, guilt and frustration which arise in such circumstances could be alleviated, and the pos sibility of obtaining a truly informed consent - ab area of concern in our study - increased.

We believe that potential pitfalls can be avoided bi CECs having a clear sense of purpose as expressed in their terms of reference; by being consultative and noo prescriptive, and by having a membership which is multidisciplinary and ethically and legally trained? However, they should not try to usurp the role of court and their primary purpose should not therefore be case decision. In the UK, courts have given cleaft signals as to the cases with which they wish to be्E involved and the presence of a lawyer on the CEC fow both education and advice would be helpful. Clinicd ethics committees are innovative and therefore shoulf be accountable, evaluated and audited.

At a local level few satisfactory alternatives for ethical debate, analysis and policy-making exis Local research ethics committees have a differers remit, are prescriptive and their workload does nof permit a dual function. Unit or socio-psychologicat meetings are multidisciplinary but may fail to provide structure or education, and to avoid bias and 
be accountable. Some larger centres do employ ethicists with specific knowledge and training in bioethics and health care law, but, though numbers are increasing there are relatively few such individuals in UK practice. Moreover, this approach may not avoid bias or permit a broad enough perspective on ethical issues. ${ }^{9}$

At a wider level it could be argued that both statute, for example the Children Act 1989 and common law, for example re $\mathrm{B}$, re $\mathrm{C}$, re $\mathrm{J}^{17-19}$ have a role in deciding such issues as withholding or withdrawing treatment, but the law has been generally reluctant to be involved in issues of public policy or morality. Rather its function has been, as Lee argues, 20 to provide for a minimum standard of behaviour. This cannot be the sole solution of moral problems. However, access to legal opinion would be necessary, if only to protect members of CECs from criminal prosecution or civil action. In the US some states have provided immunity from prosecution to members of statutory committees ${ }^{21}$ but the status of a UK committee would be far from clear.

Warnock has argued for a properly constituted national ethics committee, similar to the President's Commission, whose remit would be to examine a wide range of issues arising in both medical practice and research, in response to the public need for candour. ${ }^{22}$ Although such a group might well have some relationship with local CECs its role would surely be to examine larger issues for which there was no local consensus. An additional function of local CECs could therefore be to submit issues to a national committee. As yet, apart from institutions such as the Nuffield Council for Bioethics, we do not seem to have moved significantly toward the formation of a national group; perhaps establishing local CECs could give the process some impetus.

We would therefore advocate the formation of CECs, with the safeguards that we have outlined. Such groups need to be accountable and accessible; for case analysis at least, patients and proxys should have access. Recommendations made by committees should be the subject of review and audit to determine whether they adequately reflect current ethical and legal guidelines.

Comparison between committees having different modes of functioning would be valuable and instructive. We hope that this paper will stimulate debate on the nature and function of ethics committees in the UK, and indeed internationally.

Victor $F$ Larcher, $M A, M B, F R C P$, is an Honorary Consultant Paediatrician at the Great Ormond Street Hospital for Children, London. Bryan Lask, MB, MPhil, FRCPsych, is a Consultant Psychiatrist at the same hospital and fean $M M c$ Carthy, MA, SRN, RSCN, is Senior Nurse Lecturer in Health Care Ethics and Law, also at the Great Ormond Street Hospital for Children.

\section{References}

1 Lantos JD, Tyson JE, Allen A, Frader J, Hack M, et al. Withholding or withdrawing life sustaining treatment in neonatal intensive care: issues for the 1990s. Archives of Disease in Childhood 1994; 71: 218-223.

2 Doyal L, Wilsher D. Towards guidelines for withholding or withdrawing of life-prolonging treatment in neonatal medicine. Archives of Disease in Childhood 1994; 70: 66-70.

3 Shield JPH, Baum JD. Children's consent to treatment. British Medical fournal 1994; 308: 1182-3.

4 Devereux JA, Jones DPH, Dickenson DL. Can children withhold consent to treatment? British Medical fournal 1993; 306: 1459-61.

5 Klein $\mathrm{R}$. On the Oregon trail: rationing health care more politics than science. British Medical fournal 1991; 302: 1-2.

6 Samuels MP, McClaughlin W, Jacobson RR, Poets CF, Southall DP. Fourteen cases of imposed upper airways obstruction. Archives of Disease in Childhood 1992; 62: 102-70.

7 Fost N, Cranford RE. Hospital ethics committees: administrative aspects. Fournal of the American Medical Association 1985; 253: 2687-92.

8 Rosner F. Hospital medical ethics committees: a review of their development. Fournal of the American Medical Association 1985; 253: 2693-7.

9 Andereck WS. Development of a hospital ethics committee: lessons from five years of case consultations. Cambridge Quarterly of Health Ethics 1992; 1: 41-50.

10 Thornton JG, Lilford RJ. Education and debate. Clinical ethics committee. British Medical fournal 1995; 311: 667-9.

11 Teal K. The physician's dilemma, a doctor's view. What law should be. Baylor Law Review 1975; 27: 6-9.

12 President's Commission for the Study of Ethical Problems in Medicine and Biomedical and Behavioural Research. Deciding to forgo life sustaining treatment: a report on the ethical, medical and legal issues in treatment decisions. Washington DC: Government Printing Office, 1983.

13 Lantos JD. Baby Doe case five year later: implications for child health. New England Fournal of Medicine 1987; 317: 444-7.

14 Lo B. Behind closed doors. Promises and pitfalls of ethics committees. New England fournal of Medicine 1987 ; 317: 46-50.

15 Judicial Council of the American Medical Association. Guidelines for ethics committees in health care institutions. Fournal of the American Medical Association 1985; 253: 2698-99.

16 Weatherall DJ. The inhumanity of medicine. Time to stop and think. British Medical fournal 1994; 309: 1671-72.

$17 \mathrm{ReC}$ (a minor) [1981] 2 ALL ER $728 \mathrm{CA}$.

$18 \mathrm{ReJ}$ (a minor) [1990] 3 ALL ER $930 \mathrm{CA}$.

19 ReB (a minor) [1981] 1 WLR 1421 CA.

20 Lee SM. Law and morals. Oxford: Oxford University Press, 1986: 84-92.

21 Fleetwood J, Unger SS. Institutional ethics committees and the shield for immunity. Annals of Internal Medicine 1994; 120: 320-5.

22 Warnock M. A national ethics committee. British Medical fournal 1988; 297: 1626-7. 